\title{
Chronic ethanol treatment: Effects on the activation of brain beta-endorphin system by novelty
}

\author{
C. DALMAZ, C. A. NETTO, C. B. OLIVEIRA NETTO, C. A. FIN, and I. IZQUIERDO \\ Instituto de Biociencias, Universidade Federal do Rio Grande do Sul, Pôrto Alegre, RS, Brasil
}

\begin{abstract}
Chronic ethanol ingestion in rats abolishes novelty-induced antinociception, as measured by a tailflick method. This treatment also inhibited the posttraining facilitatory effect of naloxone and the posttraining amnesic effect of $\beta$-endorphin in a step-down inhibitory avoidance task. Measurement of hypothalamic $\beta$-endorphin-like immunoreactivity ( $\beta$-EPLIR) shows that there is a decrease in the levels of this peptide in chronic ethanol-treated rats. Exposure to a novel situation, which causes a decrease of $\beta$-EPLIR in control (water-treated) rats, had no effect in ethanol-treated rats. Taken together, these results suggest that chronic ethanol treatment decreases hypothalamic $\beta$-endorphin levels and makes this system unresponsive to novelty.
\end{abstract}

Training paradigms that involve exposure to a new environment or a new task are followed by a decrease of hypothalamic $\beta$-endorphin-like immunoreactivity in rats, which is currently interpreted as an activation of the brain $\beta$-endorphin system (Izquierdo et al., 1984; Izquierdo \& Netto, 1985a, 1985b). The $\beta$-endorphin that is released probably plays a role in memory modulation. Intraperitoneal and intracerebroventricular posttraining naloxone administration facilitates retention of a variety of aversive and nonaversive tasks (Gallagher, 1985; Gallagher \& Kapp, 1978; Izquierdo, 1979, 1984; Izquierdo \& Netto, 1985a, 1985b; Messing et al., 1979). Posttraining intraperitoneal or intracerebroventricular $\beta$-endorphin administration depresses retention, and its effect is competitively antagonized by naloxone (Izquierdo, 1989; Izquierdo \& Dias, 1983, 1985; Izquierdo \& Netto, 1985a, 1985b; Izquierdo, Perry, Dias, Souza, et al., 1981). These effects are explained in terms of an endogenous state dependency induced by $\beta$-endorphin released in response to the novelty inherent in the training session. In support of this view, it has been demonstrated that naloxone is not effective when administered to animals exposed to non-novel situations (Bostock, Gallagher, \& King, 1988; Del Cerro \& Borrell, 1985; Izquierdo, 1989; Netto, Dias, \& Izquierdo, 1986) or to animals prevented from releasing $\beta$-endorphin by a prior depletion (Izquierdo \& McGaugh, 1985), and that a second, pretest injection of $\beta$-endorphin reverses the memory impairment induced by a posttraining administration of this peptide (Izquierdo, 1989; Izquierdo \& Netto, 1985a).

A $\beta$-endorphin involvement has also been suggested in novelty-induced antinociception (Netto, Siegfried, \& Izquierdo, 1987; Siegfried, Netto, \& Izquierdo, 1987).

Correspondence should be addressed to Carla Dalmaz, Centro de Memoria, Departamento de Bioquimica, Instituto de Biociencias, UFRGS (centro), 90049, Pôrto Alegre, RS, Brasil.
It has been shown that a 2-min exposure of rats to a novel environment is followed by a mild analgesia as measured by the tailflick method (Siegfried, Netto, \& Izquierdo, 1987). The effect lasts between 10 and $30 \mathrm{~min}$; it is not seen after a second exposure to the environment, and it is reversed by the opioid antagonist naltrexone. Since other opioids do not seem to be released by nonpainful novel situations, as is $\beta$-endorphin (Carrasco et al., 1982; Izquierdo \& Netto, 1985a, 1985b), it has been speculated that the antinociception is due to the novelty-induced release of hypothalamic $\beta$-endorphin.

Recent studies suggest that chronic ethanol affects the metabolism of $\beta$-endorphin and its related neuropeptides in the rat central nervous systems. For example, it has been reported that the synthesis and/or release of $\beta$-endorphin and its precursor molecules, proopiomelanocortin (POMC) and $\beta$-lipotropin ( $\beta$-LPH), increases (Gianoulakis, 1983; Gianoulakis \& Barcomb, 1987; Gianoulakis, Chan, Kalant, \& Chretien, 1983; Gianoulakis \& Gupta, 1986; Seizinger, Bovermann, Hollt, \& Herz, 1984) or decreases (Gambert, Pontzer, \& Barboriak, 1981; Schulz, Wuster, Duka, \& Herz, 1980; Seizinger, Hollt, \& Huy, 1984) in rats consuming ethanol for 2 or 3 weeks; the discrepancies may be due to the different modes of alcohol administration used in these studies. A similar treatment can attenuate posttraining or pretest drug effects on memory attributable to influences on the endogenous $\beta$-endorphin that is released by training (Dalmaz, Fin, Oliveira, \& Izquierdo, 1989).

The purpose of this study was to determine if the activation of the hypothalamic $\beta$-endorphin system by novelty is affected by a chronic ethanol treatment, by verifying the effect of novelty on the antinociception and the effect of posttraining $\beta$-endorphin and naloxone on retention of a step-down inhibitory avoidance task, and by measuring the $\beta$-endorphin-like immunoreactivity before and after exposure of the animals to a new environment. 


\section{METHOD}

\section{Treatment}

The chronic ethanol treatment used has been described by Dalmaz et al. (1989). Forty-day-old female Wistar rats from our breeding stock were submitted to the following schedule: 1 day of water deprivation followed by exposure to a series of increasingly concentrated ethanol solutions as the sole drinking fluid source $(2 \%, 4 \%$, and $6 \%$ [v:v] for 2 days each, $8 \%$ for 4 days, $10 \%$ for 6 days, and, finally, $12 \%$ for 4-5 weeks). Control animals of the same age received tap water.

\section{Antinociception Measurement}

Antinociception was assessed with a tailflick apparatus (Siegfried, Frischknecht, Riggio, \& Waser, 1987). Rats were wrapped in a towel and placed in the apparatus; the light source positioned below the tail was focused on a point $2.3 \mathrm{~cm}$ rostral to the tip of the tail. Deflection of the tail activated a photocell and automatically terminated the trial. Light intensity was adjusted so as to obtain a baseline tailflick latency (TFL) of 3 to $6 \mathrm{sec}$. A cutoff time of $10 \mathrm{sec}$ was used to prevent tissue damage.

The general procedure was as follows: On Day 1, the subjects were familiarized with the procedure; a baseline TFL value was thus obtained for each animal. Following this, each rat was placed alone, for $2 \mathrm{~min}$, in a waiting cage (a cage just like its home cage, but not containing other animals) and then taken back to its home cage. On Day 2, the animals were submitted to the TFL measurement twice: immediately before and $2 \mathrm{~min}$ after exposure to a new environment for $2 \mathrm{~min}$. The animals remained alone in the waiting cage, either between exposure to this experimental situation and the second TFL measure (experimental group) or between both TFL measures (control group).

\section{Step-Down Inhibitory Avoidance}

The animals were trained and tested for the one-way step-down inhibitory avoidance task described by Izquierdo and Netto (1985a) and Izquierdo and Ferreira (1989), using a $50 \times 25 \times 25 \mathrm{~cm}$ plywood box with a glass-wall front and a floor consisting of $1-\mathrm{mm}$ bronze bars spaced $10 \mathrm{~mm}$ apart. The left end of the grid was covered with a 5-cm-high, 25-cm-wide, and 7.5-cm-long wood platform. During the training trial, the animals were gently held by their bodies and lowered onto the platform with their noses pointing to the rear left corner, at which time a timer was activated. The timer measured the latency to step down (i.e., with four paws on the grid), at which time an intermittent footshock $(0.3$ or $0.4 \mathrm{~mA}, 60 \mathrm{~Hz})$ was delivered until the animal climbed back onto the platform. Immediately after the training trial, the animals were withdrawn from the box, and the water- and ethanol-treated rats were subdivided into three subgroups. Each subgroup received, i.p., one of the following posttraining treatments: saline $(1.0 \mathrm{ml} / \mathrm{kg}), \beta$-endorphin (Sigma, $0.2 \mu \mathrm{g} / \mathrm{kg}$ ), or naloxone-HCl (Endo, $0.4 \mathrm{mg} / \mathrm{kg}$ ). All drugs were dissolved in saline in a volume corresponding to $1.0 \mathrm{ml} / \mathrm{kg}$. Twenty-four hours after the training trial, the animals were again placed on the platform. The difference in step-down latency between the test and the training trial was used as the measure of retention.

\section{$\beta$-Endorphin-Like Immunoreactivity Measurement}

Water- and ethanol-treated rats were exposed to a new environment for $2 \mathrm{~min}$. After that, they remained alone in a waiting cage for 2-3 min. The animals were then killed by decapitation. The brain of each animal was quickly removed and placed on an inverted Petri dish on $\mathrm{NaCl}$-ice at $-5^{\circ}$ to $-10^{\circ} \mathrm{C}$, where the hypothalamus (including the preoptic area) was dissected. The hypothalamus was extracted in $2 \mathrm{ml} 1 \mathrm{~N}$ acetic acid at $98^{\circ} \mathrm{C}$ for $15 \mathrm{~min}$, chilled to less than $4^{\circ} \mathrm{C}$, homogenized, stirred for $3 \mathrm{~h}$ at $4^{\circ} \mathrm{C}$, and centrifuged at $12,000 \times \mathrm{g}$ for $10 \mathrm{~min}$. The supernatant solutions were frozen. $\beta$-endorphin was measured by radioimmunoassay with the use of a Du Pont kit. The assay cross-reacts with $\beta$-lipotropin ( $50 \%$ ) but not with alpha or gamma endorphin or with enkephalins. The results reported here were not corrected for the presence of the larger precursor molecules, which account for about one-third of the immunoreactivity present in the hypothalamus (Rossier et al., 1977). The extraction and assay procedures were the same as those recommended by Rossier et al. (1977) and have been extensively used in our laboratory (Carrasco et al., 1982; Izquierdo, Perry, Dias, Orsingher, \& Carrasco, 1981; Izquierdo, Perry, Dias, Souza, et al., 1981; Lzquierdo et al., 1980; Perry, Dias, Carrasco, \& Izquierdo, 1983). Control animals were taken from their home cages and killed immediately.

\section{Statistical Analysis}

Tailflick latency and retention scores in the step-down inhibitory avoidance task were submitted to a Kruskal-Wallis analysis of variance, followed by individual Mann-Whitney $U$ tests (two-tailed) when appropriate. Training step-down latencies and radioimmunoassay data were submitted to an analysis of variance, followed, if necessary, by a Duncan multiple range test.

\section{RESULTS}

Postexposure minus preexposure TLFs are shown in Table 1. Preexposure values were not different between the groups $(p>.05)$. Exposure to a novel environment increased TFL differences in water-treated rats $(p<.05)$, as described by Siegfried, Netto, and Izquierdo (1987) and Netto et al. (1987). The effect was not observed in the ethanol-treated group.

Results from the inhibitory avoidance task are shown in Table 2. In the water-treated animals, naloxone increased retention, whereas $\beta$-endorphin reduced memory scores, which confirmed previous results (Gallagher, King, \& Young, 1983; Izquierdo, 1979, 1989; Izquierdo \& Dias, 1983; Izquierdo \& Netto, 1985a; Izquierdo et al., 1980; Messing et al., 1979). In the ethanol-treated rats, neither the effect of naloxone nor that of $\beta$-endorphin was demonstrable.

Exposure of the water-treated animals to the novel environment was followed by a marked reduction of hypothalamic $\beta$-endorphin-like immunoreactivity (Figure 1), as has been reported previously (Izquierdo \& Netto,

Table 1

Median (and Interquartile Range) Increase of Tail-Flick Latency (TFL) Expressed as the Difference Between a Measure Carried Out 2 min after Exposure of Rats to a New Environment and Another Measure Carried Out Immediately before the Exposure

\begin{tabular}{cccc} 
& \multicolumn{2}{c}{ TFL Difference (in sec) } \\
\cline { 3 - 4 } Group & $n$ & Median & Interquartile Range \\
\hline \multirow{3}{*}{ Control } & 11 & Water-treated Group & \\
Novelty & 16 & 0.11 & $(-0.24 / 0.41)$ \\
& & 0.51 & $(0.03 / 0.97)^{*}$ \\
Control & 11 & -0.07 & $(-2.06 / 1.42)$ \\
Novelty & 20 & 0.02 & $(-0.53 / 0.46)$ \\
\hline
\end{tabular}

Note-Control groups were not submitted to novel situations. ${ }^{*} p<.05$, two-tailed Mann-Whitney $U$ test. 
Table 2

Retention Scores in a Step-down Inhibitory Avoidance Task of Water-treated and Ethanol-treated Rats

\begin{tabular}{lcr}
\hline \multirow{2}{*}{$\begin{array}{c}\text { Posttraining } \\
\text { Treatment }\end{array}$} & \multicolumn{2}{c}{ Retention Scores } \\
\cline { 2 - 3 } Saline & Pater Treated & Ethanol Treated \\
Naloxone & $18.0(10.2 / 4.0)$ & $20.6(9.4 / 30.1)$ \\
& $106.3(44.0 / 180.0)^{*}$ & $22.1(6.9 / 56.5)$ \\
Saline & Panel B & \\
B-endorphin & $180.0(115.2 / 180.0)$ & $180.0(79.6 / 180.0)$ \\
\hline
\end{tabular}

Note-Animals received saline, naloxone $(0.4 \mathrm{mg} / \mathrm{kg})$, or B-endorphin $(2 \mu \mathrm{g} / \mathrm{kg})$ i.p. immediately after training. Data are reported as the median (interquartile range) test minus training step-down latency. Panel $\mathrm{A}$ : $0.2 \mathrm{~mA}$. Panel B: $0.3 \mathrm{~mA} . N=11$ animals per group in Panel $A$ and 13 animals per group in Panel B.

1985a, 1985b; Izquierdo, Perry, Dias, Orsingher, \& Carrasco, 1981; Izquierdo et al., 1980; Izquierdo et al., 1984; Netto et al., 1985). Ethanol-treated animals showed a significantly lower resting or "basal" $\beta$-endorphin-like immunoreactivity level than did water-treated animals $(p<.05)$. When exposed to a new environment, ethanoltreated rats showed no changes of $\beta$-endorphin-like immunoreactivity.

\section{DISCUSSION}

The present study confirmed previous results (Netto et al., 1987; Siegfried, Netto, \& Izquierdo, 1987), show-

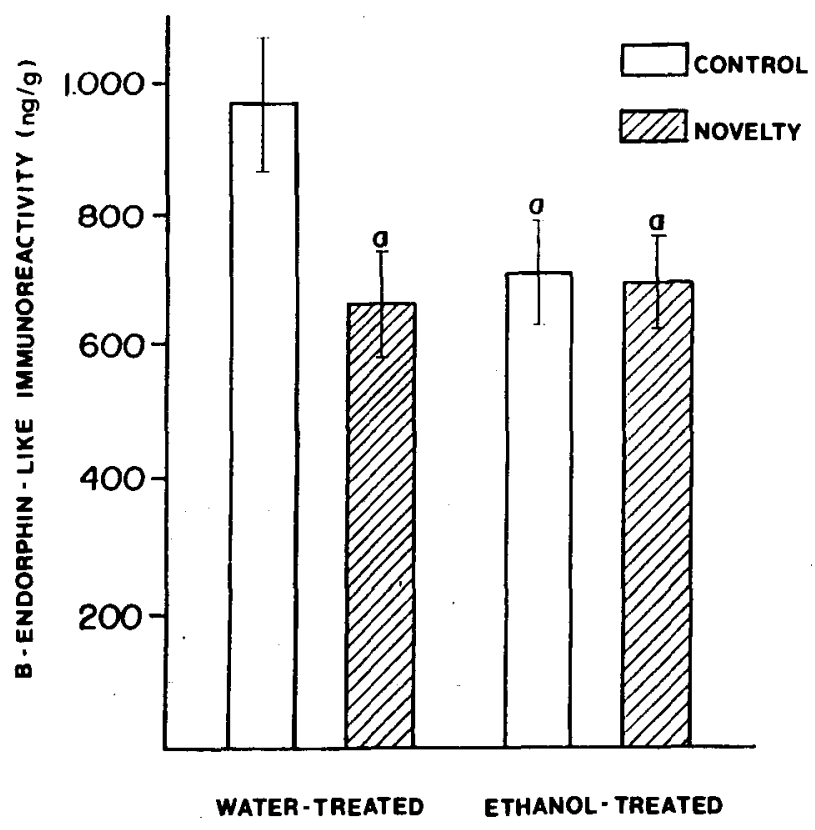

Figure 1. Effect of exposure to a new environment on hypothalamic $\beta$-endorphin-like immunoreactivity of control (water-treated) and ethanol-treated rats. Results are reported as means $\pm S E M$. $n=11-14$ animals per group. $a=$ significant difference from the water-treated, not-exposed-to-novelty group at the $p<.05$ level by the Duncan multiple-range test. ing that exposure of rats to a new environment resulted in a significant increase in tailflick latency. This antinociception is blocked by naloxone, and it has been proposed that hypothalamic $\beta$-endorphin, which is released when the animal is exposed to novelty, is responsible for this effect (Siegfried, Frischknecht, et al., 1987; Siegfried, Netto, \& Izquierdo, 1987). Thus, the absence of the novelty-induced antinociception in rats exposed to chronic ethanol treatment points to a possible alteration in the hypothalamic $\beta$-endorphin system.

In the step-down inhibitory avoidance task, posttraining naloxone and $\beta$-endorphin produced effects on retention in the control (water-treated) animals, as reported before (Gallagher et al., 1983; Izquierdo, 1979, 1989; Izquierdo \& Dias, 1983; Izquierdo \& Netto, 1985a; Izquierdo et al., 1980; Messing et al., 1979). In the ethanoltreated rats, posttraining naloxone did not cause memory facilitation and posttraining $\beta$-endorphin did not cause decreased retrieval. Since the effect of naloxone depends on the previous activation of the brain $\beta$-endorphin system that occurs after new training situations (Izquierdo, 1989; Izquierdo \& Netto, 1985a, 1985b; Izquierdo, Perry, Dias, Orsingher, \& Carrasco, 1981; Izquierdo et al., 1980; Izquierdo et al., 1984; Netto et al., 1985), the lack of facilitatory effect of naloxone given after training supports the hypothesis that chronic ethanol treatment causes an alteration in the hypothalamic $\beta$-endorphin system response to novelty. The absence of $\beta$-endorphin effect also agrees with this hypothesis.

In the control (water-treated) rats, exposure of the animals to a new environment was followed by a decrease of hypothalamic $\beta$-endorphin-like immunoreactivity $(\beta$ EPLIR). As has been discussed previously (Carrasco et al., 1982; Izquierdo, Perry, Dias, Orsingher, \& Carrasco, 1981; Izquierdo et al., 1980), the rapid decrease of $\beta$ EPLIR caused by novelty can be explained best by the release and subsequent degradation of the substance and/or its precursors. Chronic ethanol treatment induced a decrease in the content of hypothalamic $\beta$-EPLIR. These results also indicate that exposure of the treated animals to novelty did not induce a further decrease in $\beta$-EPLIR, indicating that there is no novelty-induced release of $\beta$-endorphin and/or cross-reacting substances. As mentioned earlier, the radioimmunoassay procedure used in the present study cross-reacts with $\beta$-LPH $(50 \%)$, and POMC (1\%); however, these larger molecules account for less than $10 \%$ of $\beta$-EPLIR in the diencephalon (Rossier et al., 1977; Bloom et al., 1978), which is less than the percentage decrease observed in novelty-exposed controls or in ethanol-treated rats.

The content of $\beta$-EPLIR in the hypothalamus reflects the net result of three processes: biosynthesis, release, and degradation. The decreased levels of basal $\beta$-EPLIR suggest decreased synthesis and/or increased turnover of $\beta$-endorphin in the brain of ethanol-treated rats.

Recent investigations have shown that chronic ethanol treatment leads to an alteration in the rate of $\beta$-endorphin metabolism in the pituitary glands and in the brains of rats consuming ethanol (Gambert et al., 1981; Gianou- 
lakis, 1983; Gianoulakis \& Barcomb, 1987; Gianoulakis et al., 1983; Gianoulakis \& Gupta, 1986; Schulz et al., 1980; Seizinger, Bovermann, et al., 1984; Seizinger, Hollt, \& Huy, 1984). The different methods of ethanol administration induced different alterations in the tissue levels of $\beta$-endorphin in several areas of the brain and the pituitary. For example, in contrast to chronic application of ethanol in tap water, chronic treatment of rats with ethanol in liquid diet resulted in an increase in the biosynthesis of $\beta$-endorphin-related peptides in the pituitary (Seizinger, Bovermann, et al., 1984). The disparate results indicate that mode of ethanol administration must be considered, and that it may contribute to several discrepancies in alcohol research.

Other brain areas, such as the septum and the amygdala, have been shown to be involved in the effects of opioids on learning and memory (Bostock et al., 1988; Gallagher \& Kapp, 1978), but the hypothalamus is the only structure where $\beta$-endorphin release has been demonstrated (Izquierdo \& Netto, 1985a, 1985b; Izquierdo et al., 1984)-it is seen only when animals are exposed to the training for the first time. It is possible, however, that ethanol treatment may have an effect on $\beta$-endorphin levels in other brain regions; this possibility can be explored in future investigations.

In conclusion, then, the present results show that chronic ethanol treatment causes a decrease in the hypothalamic $\beta$-EPLIR and makes the $\beta$-endorphin system unresponsive to novclty, which can explain the lack of effect of posttraining naloxone and $\beta$-endorphin in step-down inhibitory avoidance and also explain the absence of noveltyinduced antinociception in these rats. However, the mechanism by which ethanol induces these changes is not clear. Further experiments on the effects of ethanol on various neurotransmitter systems and their relationship with the endogenous opioid peptides should be performed. Such -studies may provide an insight into the clinical and behavioral actions of ethanol.

\section{REFERENCES}

Bloom, F. E., Rossier, J., Battenberg, E. L. F., BAyon, A., French, E., Henriksen, S. J., Siggins, G. R., Segal, D., Browne, R., Ling, N., \& Guillemin, R. (1978). B-Endorphin: Cellular localization, electrophysiology and behavioral effects. In E. Costa \& M. Trabucci (Eds.), The endorphins (pp. 89-109). New York: Raven Press.

Bostock, E., Gallagher, M., \& King, R. A. (1988). Effects of opioid microinjections into the septal area on spatial memory in rats. Behavioral Neuroscience, 102, 643-652.

Carrasco, M. A., Dias, R. D., Perry, M. L. S., Wofchuk, S. T., SOUZA, D. O., \& IZQuiERDo, I. (1982). Effect of morphine, ACTH, epinephrine, Met-, Leu- and des-Tyr-Met-enkephalin on B-endorphinlike immunoreactivity of the rat brain. Psychoneuroendocrinology, 34, 352-357.

Dalmaz, C., Fin, C. A., Oliveira, C. B., Izquierdo, I. (1989). Chronic ethanol ingestion selectively affects modulation of memory. Brazilian Journal of Medical \& Biological Research, 22, 403-406.

Del Cerro, S., \& Borrell, J. (1985). Naloxone influences retention behavior depending on the degree of novelty inherent to the training situation. Physiology \& Behavior, 35, 667-671.

Gallagher, M. (1985). Re-viewing modulation of learning and memory. In N. M. Weinberger, J. L. McGaugh, \& G. Lynch (Eds.), Memory systems of the brain (pp. 311-334). New York: Guilford Press.

Gallagher, M., \& KAPP, B. S. (1978). Opiate administration into the amygdala: Effects on memory processes. Life Sciences, 23, 1973-1978.

Gallagher, M., King, R. A., Young, N. B. (1983). Opiate antagonists improve spatial memory. Science, 221, 975-976.

Gambert, S. R., Pontzer, C. H., Barboriak, J. J. (1981). Effect of ethanol consumption on central nervous system (CNS) Betaendorphin and ACTH. Hormonal \& Metabolic Research, 13, 242-243.

Gianoulakis, C. (1983). Long-term ethanol alters the binding of $3 \mathrm{H}$ opiates to brain membranes. Life Sciences, 33, 725-733.

Gianoulakis, C., BARCOMB, A. (1987). Effect of acute ethanol " in vivo" and "in vitro" on the B-endorphin system in the rat. Life Sciences, 40, 19-28.

Gianoulakis, C., Chan, J. S. B., Kalant, H., Chretien, M. (1983). Chronic ethanol treatment alters the biosynthesis of Bendorphin by the rat neurointermediate lobe. Canadian Joumal of Physiology \& Pharmacology, 61, 967-976.

Gianoulakis, C., GuPTA, A. (1986). Inbred strains of mice with variable sensitivity to ethanol exhibit differences in the content and processing of B-endorphin. Life Sciences, 39, 2315-2325.

IZQUIERDo, I. (1979). Effect of naloxone and morphine on various forms of memory in the rat: Possible role of endogenous opiate mechanisms in memory consolidation. Psychopharmacology, 66, 199-203.

IZQUIERDO, I. (1984). Endogenous state-dependency: Memory depends on the relation between the neurohumoral and hormonal states present after training and at the time of testing. In G. Lynch, J. L. McGaugh, \& N. M. Weinberger (Eds.), Neurobiology of learning and memory (pp. 65-77). New York: Guilford Press.

IZQUIERDO, I. (1989). Different forms of posttraining memory processing. Behavioral \& Neural Biology, 51, 171-202.

IZquierdo, I. \& DiAs, R. D. (1983). Effect of ACTH, epinephrine, B-endorphin, naloxone, and of the combination of naloxone or $B$ endorphin with ACTH or epinephrine on memory consolidation. Psychoneuroendocrinology, 8, 81-87.

IZQUIERDO, I., \& DiAS, R. D. (1985). Influence on memory of posttraining and pre-test injections of $\mathrm{ACTH}$, vasopressin, epinephrine, or B-endorphin, and their interaction with naloxone. Psychoneuroendocrinology, 10, 165-172.

Izquierdo, I., \& Ferreira, M. B. (1989). Diazepam prevents posttraining drug effects related to state dependency, but not post-training memory facilitation by epinephrine. Behavioral \& Neural Biology. 44, 228-238.

IZquiERD, I., \& MCGAUGH, J. L. (1985). Effect of a novel experience prior to training or testing on retention of an inhibitory avoidance task in mice: Involvement of an opioid system. Behavioral \& Neural Biology, 44, 228-238.

IzquiERDo, I., NetTo, C. A. (1985a). The role of B-endorphin in memory regulation. Annals of the New York Academy of Sciences, 444, 162-177.

IZQUIERDO, I., NETTo, C. A. (1985b). Factors that influence test session performance measured 0,3 , or $6 \mathrm{~h}$ after inhibitory avoidance training. Behavioral \& Neural Biology, 43, 260-273.

Izquierdo, l., Perry, M. L. S., Dias, R. D., Orsingher, O. A., \& Carrasco, M. A. (1981). Effect of training and testing rats in two different behavioral paradigms on brain B-endorphin immunoreactivity. Arquivos de Biologia e Tecnologia (Parana), 24, 327-331.

Izquierdo, I., Perry, M. L., Dias, R. D., Souza, D. O., Elisabetsky, E., Carrasco, M. A., Orsingher, O. A., NeTTo, C. A. (1981). Endogenous opioids, memory modulation and state dependency, In J. L. Martinez, Jr., R. A. Jensen, R. B. Messing, H. Rigter, \& J. L. McGaugh (Eds.), Endogenous Peptides and Leaming and Memory Processes (pp. 269-290). New York: Academic Press.

Izquierdo, I., Souza, D. O., Carrasco, M. A., Dias, R. D., Perry, M. L., Eisinger, S., Elisabetsky, E., Vendite, D. A. (1980). Beta-endorphin causes retrograde amnesia and is released from the rat brain by various forms of training and stimulation. Psychopharmacology, 70, 173-177.

Izquierdo, I., Souza, D. O., Dias, R. D., Perry, M. L., Car- 
Rasco, M. A., Volkmer, N., \& NetTo, C. A. (1984). Effect of various behavioral training and testing procedures on brain B-endorphinlike immunoreactivity and the possible role of B-endorphin in behavioral regulation. Psychoneuroendocrinology, 9, 381-389.

Messing, R. B., Jensen, R. A., Martinez, J. L., JR., Spiehler, V. R., Vasquez, B. J., Somireu-Mourat, B., Liang, K. C., \& McGaugh, J. L. (1979). Naloxone enhancement of memory. Behavioral \& Neural Biology, 27, 266-275.

Netto, C. A., Cavalheiro, E. A., Carrasco, M. A., Volkmer, N., DiAs, R. D., \& IzQUIERDo, I. (1985). Response of the rat brain Bendorphin system to novelty: Importance of the fornix connection. Behavioral \& Neural Biology, 43, 37-46.

Netto, C. A., Dias, R. D., \& IzQuierdo, I. (1986). Training in an open field: Simultaneous learning of habituation and of a water-finding task, and differential effect of post-training naloxone, B-endorphin, Leu-enkephalin, and electroconvulsive shock. Psychoneuroendocrinology, 11, 437-446.

Netto, C. A., Siegfried, B., \& Izquierdo, I. (1987). Analgesia induced by exposure to a novel environment in rats: Effect of concurrent and post-training stressful stimulation. Behavioral \& Neural Biology, 48, 304-309.

Perry, M. L. S., Dias, R. D., Carrasco, M. A., \& Izquierdo, I. (1983). Step-down inhibitory avoidance training and B-endorphin-like immunoreactivity of rat hypothalamus and plasma. Brazilian Journal of Medical \& Biological Research, 16, 339-343.

Rossier, J., Bayon, A., Vargo, T., Ling, N., Guillemin, R., \&
BLoom, F. E. (1977). Radioimmunoassay of brain peptides: Evaluation of a methodology for the assay of B-endorphin and enkephalin. Life Sciences, 21, 847-852.

Schulz, R., Wuster, M., Duka, T., \& Herz, A. (1980). Acute and chronic ethanol treatment changes endorphin levels in brain and pituitary. Psychopharmacology, 68, 221-227.

Seizinger, B. R., BovermanN, K., Hollt, V., \& Herz, A. (1984). Enhanced activity of the B-endorphinergic system in the anterior and neurointermediate lobe of the rat pituitary after chronic treatment with ethanol liquid diet. Journal of Pharmacology \& Experimental Therapeutics, 230, 455-461.

Seizinger, B. R., Hollt, V., \& Huy, A. (1984). Effects of chronic ethanol treatment on the "in vitro" biosynthesis of proopiomelanocortin and its posttranslational processing to B-endorphin in the intermediate lobe of the rat pituitary. Journal of Neurochemistry, 43, 607-613.

Siegfried, B., Frischinecht, H. R., Riggio, G., \& Waser, P. G. (1987). Preexposure to a nonaggressive opponent prevents lowintensity, social-conflict analgesia in mice. Behavioral Neuroscience, $101,423-426$

Siegfried, B., Netto, C. A., \& IzQuierdo, I. (1987). Exposure to novelty induces naltrexone reversible analgesia in rats. Behavioral Neuroscience, 101, 303-308.

(Manuscript received April 10, 1990; revision accepted for publication August 22, 1990.) 